\title{
Some Fixed Point Theorems in b-metric Space
}

\author{
Pankaj Kumar Mishra*, Shweta Sachdeva, S. K. Banerjee \\ Department of Mathematics, University of Petroleum \& Energy Studies, P.O. Bidholi, Via Prem Nagar, Dehradun (Uttarakhand), India \\ *Corresponding author:pk_mishra009@yahoo.co.in \\ Received January 13, 2014; Revised February 18, 2014; Accepted February 26, 2014
}

\begin{abstract}
In this paper we have obtained some fixed point theorems on $b$ - metric space which is an extension of a fixed point theorem by Hardy [13] and Reich [20].
\end{abstract}

Keywords: b-metric space, fixed point

Cite This Article: Pankaj Kumar Mishra, Shweta Sachdeva, and S. K. Banerjee, "Some Fixed Point Theorems in b-metric Space." Turkish Journal of Analysis and Number Theory, vol. 2, no. 1 (2014): 19-22. doi: 10.12691/tjant-2-1-5.

\section{Introduction}

In the development of non-linear analysis, fixed point theory plays a very important role. Also, it has been widely used in different branches of engineering and sciences.

Metric fixed point theory is an essential part of mathematical analysis because of its applications in different areas like variational and linear inequalities, improvement, and approximation theory. The fixed point theorem in metric spaces plays a significant role to construct methods to solve the problems in mathematics and sciences.

Although metric fixed point theory is vast field of study and is capable of solving many equations. To overcome the problem of measurable functions w.r.t. a measure and their convergence, Czerwik [8] needs an extension of metric space. Using this idea, he presented a generalization of the renowned Banach fixed point theorem in the b-metric spaces (see also $[9,10,11]$ ). Many researchers including Aydi [1], Boriceanu [3,4,5], Bota [6], Chug [7], Du [12], Kir [14], Olaru [15], Olatinwo [16], Păcurar [17,18], Rao [19], Roshan [21] and Shi [22] studied the extension of fixed point theorems in b-metric space.

In this paper, our aim is to show the validity of some important fixed point results into b-metric spaces.

\section{Preliminaries}

We recall some definitions and properties for b-metric spaces given by Czerwik [8].

Definition 2.1. If $M(\neq \phi)$ is a set having $s(>=1) \in \mathbb{R}$ then a self-map $\rho$ on $M$ is called a b-metric if the following conditions are satisfied:

(i) $\rho(x, y)=0$ if and only $\mathrm{x}=\mathrm{y}$;

(ii) $\rho(x, y)=\rho(y, x)$; (iii) $\rho(x, z) \leq s \cdot[\rho(x, y)+\rho(y, z)]$ for all $x, y, z \in M$. The pair $(M, \rho)$ s called a b-metric space.

From the above definition it is evident that the b-metric space extended the metric space. Here, for $\mathrm{s}=1$ it reduces into standard metric space.

Let us have a look on some example [2] of b-metric space:

Example 2.1. The space $l_{p},(0<p<1)$,

$$
l_{p}=\left\{\left(x_{n}\right) \subset R: \sum_{n=1}^{\infty}\left|x_{n}\right|^{p}<\infty\right\},
$$

together with the function $\rho: l_{p} \times l_{p} \rightarrow \mathbb{R}$ where

$$
\rho(x, y)=\left(\sum_{n=1}^{\infty}\left|x_{n}-y_{n}\right|^{p}\right)^{\frac{1}{p}}
$$

where $x=x_{n}, y=y_{n} \in l_{p}$ is a b-metric space. By an elementary calculation we obtain that

$$
\rho(x, y) \leq 2^{\frac{1}{p}}[\rho(x, y)+\rho(y, z)]
$$

Example 2.2. The space $l_{p},(0<p<1)$, of all real functions $x(t), t \in[0,1]$ such that

$$
\int_{0}^{1}|x(t)|^{p} d t<\infty
$$

is b-metric space if we take

$$
\rho(x, y)=\left(\int_{0}^{1}|| x(t)-\left.y(t)\right|^{p} d t\right)^{\frac{1}{p}}
$$

for each $x, y \in l_{p}$.

Now we present the definition of Cauchy sequence, convergent sequence and complete b-metric space. 
Definition 2.2. [8] Let $(M ; \rho)$ be a $b$-metric space then $\left\{x_{n}\right\}$ in $M$ is called

(a) A Cauchy sequence iff $\forall \epsilon>0$ there exists $n(\epsilon) \in \mathbb{N}$, such that for each $n, m \geq n(\epsilon)$ we have $\rho\left(x_{n}, x_{m}\right)<\epsilon$.

(b) convergent sequence if and only if there exist $x \in M$ such that for all $\epsilon>0$ there exists $n(\epsilon) \in \mathbb{N}$, such that for every $n \geq n(\epsilon)$ we have $\rho\left(x_{n}, x\right)<\epsilon$.

Definition 2.3. [8] 1. If $(M, \rho)$ is a b-metric space then a subset $L \subset M$ is called

(i) compact iff for every sequence of elements of $\mathrm{L}$ there exists a subsequence that converges to an element of $\mathrm{L}$.

(ii) closed iff for each sequence $\left\{x_{n}\right\}$ in $\mathrm{L}$ which converges to an element $\mathrm{x}$, we have $\mathrm{x} \in \mathrm{L}$.

2. The b-metric space is complete if every Cauchy sequence converges.

To prove the theorem 3.2 and 3.4 we will use the following lemma 2.1 [23].

Lemma 2.1. Suppose $(M, \rho)$ be a b-metric space and $\left\{y_{n}\right\}$ be a sequence in M such that

$$
\rho\left(y_{n+1}, y_{n+2}\right) \leq \lambda \rho\left(y_{n}, y_{n+1}\right), n=0,1, \ldots
$$

where $0 \leq \lambda<1$ Then the sequence $\left\{y_{n}\right\}$ is a Cauchy sequence in $M$ provided that $s . \lambda<1$.

\section{Main Result}

The following theorem is given by Reich [20]:

Theorem 3.1. Let $M$ be a complete metric space with metric $\rho$ and let $T: M \rightarrow M$ be a function with the following property

$$
\rho(T(x), T(y)) \leq a \rho(x, T(x))+b \rho(y, T(y))+c \rho(x, y)
$$

for all $x, y \in M$ where $a, b, c$ are non-negative and satisfy $a+b+c<1$. Then Thas a unique fixed point.

We have extended the above theorem 3.1 to the $b$ metric space.

Theorem 3.2. Let $M$ be a complete b-metric space with metric $\rho$ and let $T: M \rightarrow M$ be a function with the following

$\rho(T(x), T(y)) \leq a \rho(x, T(x))+b \rho(y, T(y))+c \rho(x, y)(3.1)$

$\forall \mathrm{x} ; \mathrm{y} \in \mathrm{M}$, where $a, b, c$ are non-negative real numbers and satisfy $\mathrm{a}+\mathrm{s}(\mathrm{b}+\mathrm{c})<1$ for $s \geq 1$ then $T$ has a unique fixed point.

Proof. Let $x_{0} \in M$ and $\left\{x_{n}\right\}$ be a sequence in $M$, such that

$$
x_{n}=T x_{n-1}=T^{n} x_{0}
$$

Now

$$
\begin{aligned}
& \rho\left(x_{n+1}, x_{n}\right)=\rho\left(T x_{n}, T x_{n-1}\right) \\
\leq & a \rho\left(x_{n}, T\left(x_{n}\right)\right)+b \rho\left(x_{n-1}, T\left(x_{n-1}\right)\right)+c \rho\left(x_{n}, x_{n-1}\right) \\
= & a \rho\left(x_{n}, x_{n+1}\right)+b \rho\left(x_{n-1}, x_{n}\right)+c \rho\left(x_{n}, x_{n-1}\right) \\
\Rightarrow & (1-a) \rho\left(x_{n+1}, x_{n}\right) \leq(b+c) \rho\left(x_{n}, x_{n-1}\right) \\
\Rightarrow & \rho\left(x_{n+1}, x_{n}\right) \leq \frac{(b+c)}{(1-a)} \rho\left(x_{n}, x_{n-1}\right)=p \rho\left(x_{n}, x_{n-1}\right)
\end{aligned}
$$

continuing this process we can easily say that

$$
\rho\left(x_{n+1}, x_{n}\right) \leq p^{n} \rho\left(x_{0}, x_{1}\right)
$$

This implies that $T$ is a contraction mapping.

Now, it is to show that $\left\{x_{n}\right\}$ is a Cauchy sequence in $M$.

Let $m, n>0$, with $m>n$

$$
\begin{aligned}
\rho\left(x_{n}, x_{m}\right) \leq & s\left[\rho\left(x_{n}, x_{n+1}\right)+\rho\left(x_{n+1}, x_{m}\right)\right] \\
\leq & s \rho\left(x_{n}, x_{n+1}\right)+s^{2} \rho\left(x_{n+1}, x_{n+2}\right) \\
& +s^{3} \rho\left(x_{n+2}, x_{n+3}\right)+\ldots \\
\leq & s p^{n} \rho\left(x_{0}, x_{1}\right)+s^{2} p^{n+1} \rho\left(x_{0}, x_{1}\right) \\
& +s^{3} p^{n+2} \rho\left(x_{0}, x_{1}\right)+\ldots \\
= & s p^{n} \rho\left(x_{0}, x_{1}\right)\left[1+s p+(s p)^{2}+(s p)^{3}+\ldots\right] \\
= & \frac{s p^{n}}{1-s p} \rho\left(x_{0}, x_{1}\right)
\end{aligned}
$$

Now using lemma 2.1 and taking limit $n \rightarrow \infty$ we get

$$
\lim _{n \rightarrow \infty} \rho\left(x_{n}, x_{m}\right)=0
$$

$\Rightarrow\left\{x_{n}\right\}$ is a Cauchy sequence in $M$. Since $M$ is complete, we consider that $\left\{x_{n}\right\}$ converges to $x^{*}$.

Now, we show that $x^{*}$ is fixed point of $T$. we have

$$
\begin{gathered}
\rho\left(x^{*}, T\left(x^{*}\right)\right) \leq s\left[\rho\left(x^{*}, x_{n}\right)+\rho\left(x_{n}, T\left(x^{*}\right)\right)\right] \\
\leq s\left[\rho\left(x^{*}, x_{n}\right)+\rho\left(T\left(x_{n-1}\right), T\left(x^{*}\right)\right)\right] \\
\leq s\left[\rho\left(x^{*}, x_{n}\right)+a \rho\left(x^{*}, T\left(x^{*}\right)\right)\right. \\
\left.+b \rho\left(x_{n-1}, T\left(x_{n-1}\right)\right)+c \rho\left(x_{n-1}, x^{*}\right)\right] \\
(1-a s) \rho\left(x^{*}, T\left(x^{*}\right)\right) \leq s\left[\rho\left(x^{*}, x_{n}\right)\right. \\
\left.+b \rho\left(x_{n-1}, x_{n}\right)+c \rho\left(x_{n-1}, x^{*}\right)\right] \\
\rho\left(x^{*}, T\left(x^{*}\right) \leq \frac{s \quad}{(1-a s)}\left[\rho\left(x^{*}, x_{n}\right)+b \rho\left(x_{n-1}, x_{n}\right)\right.\right. \\
\left.+c \rho\left(x_{n-1}, x^{*}\right)\right] \\
\leq\left[\rho\left(x^{*}, x_{n}\right)+b p^{n} \rho\left(x_{0}, x_{1}\right)\right. \\
\left.+c \rho\left(x_{n-1}, x^{*}\right)\right]
\end{gathered}
$$

Taking $\lim n \rightarrow \infty$, we get

$$
\begin{aligned}
& \lim _{n \rightarrow \infty} \rho\left(x^{*}, T\left(x^{*}\right)\right)=0 \\
& \Rightarrow x^{*}=T\left(x^{*}\right)
\end{aligned}
$$

$\Rightarrow x^{*}$ is the fixed point of $T$.

Now, for the uniqueness of fixed point.

Let $x$ and $y$ be two fixed points of $T$

$$
\begin{gathered}
\Rightarrow x=T(x), y=T(y) \\
\rho(x, y)=\rho(T(x), T(y)) \\
\leq a \rho(x, T(x))+b \rho(y, T(y))+c \rho(x, y)
\end{gathered}
$$

$\Rightarrow \rho(x, y) \leq c \rho(x, y)$. which is a contradiction. The proof is complete.

Now we will discuss the extension of the following theorem given by Hardy and Rogers [13] to the b-metric space as our second result in theorem 3.4. 
Theorem 3.3. Let $(M, \rho)$ be a metric space and $T: M \rightarrow M$ a mapping satisfies the following condition for all $x, y \in M$.

(i)

$$
\begin{aligned}
\rho(T x, T y) \leq & a . \rho(x, T x)+b . \rho(y, T y) \\
& +c . \rho(x, T y)+e . \rho(y, T x)+f . \rho(x, y),
\end{aligned}
$$

where $a, b, c, e$, f are nonnegative and we set $\alpha=a+b$ $+c+d+e+f$. Then

(a) If $M$ is complete metric space and $\alpha<1$ then $T$ has a unique fixed point.

(b) If (i) is modified to the condition. $x \neq y$

then this implies

$$
\begin{aligned}
\rho(T x, T y) \leq & a . \rho(x, T x)+b . \rho(y, T y) \\
& +c . \rho(x, T y)+e . \rho(y, T x)+f . \rho(x, y),
\end{aligned}
$$

and in this case we assume $M$ is compact. $T$ is continuous and $\alpha=1$, then $T$ has $a$ unique fixed point.

Here we have studied the extension of theorem 3.3 in the b-metric space.

Theorem 3.4. Let $(M, \rho)$ be a complete b-metric space and a mapping $T: M \rightarrow M$ satisfying the following condition for all $x, y \in M$.

$$
\begin{aligned}
\rho(T x, T y) & \leq a \rho(x, T x)+b \rho(y, T y) \\
& +c \rho(x, T y)+e \rho(y, T x)+f \rho(x, y)
\end{aligned}
$$

where $a, b, c, e$, fare nonnegative and we set $\alpha=a+b+$ $c+e+f$, such that $a \in\left(0, \frac{1}{2 s}\right)$.for $s \geq 1$ then $T$ has $a$ unique fixed point.

Before going to prove this theorem we require following lemma 3.1 [13].

Lemma 3.1. Let the condition 3.2 hold on $(M, \rho)$ for a self map $T$ on it. Then if $a \in\left(0, \frac{1}{2 s}\right)$ there exist $\rho<\frac{1}{2 s}$ such that

$$
\rho\left(T x, T^{2} x\right) \leq \beta \rho(x, T x) .
$$

Proof. Let $\mathrm{y}=\mathrm{Tx}$ in (3.2) and simplify to get

$$
\rho\left(T x, T^{2} x\right) \leq \frac{a+f}{1-b} \rho(x, T x)+\frac{c}{1-b} \rho\left(x, T^{2} x\right)
$$

Now using triangular inequality $\rho\left(x, T^{2} x\right) \leq s\left[\rho(x, T x)+\rho\left(T x, T^{2} x\right)\right] \quad$ so from 3.4 we obtain

$\frac{1}{s} \rho\left(T^{2} x, x\right)-\rho(T x, x) \leq \frac{a+f}{1-b} \rho(x, T x)+\frac{c}{1-b} \rho\left(x, T^{2} x\right)$

on simplifying

$$
\rho\left(T^{2} x, x\right) \leq \frac{(1+a+f-b) s}{1-b-c . s} \rho(x, T x)
$$

Now substituting inequality (3.5) into (3.4), we get

$$
\rho\left(T x, T^{2} x\right) \leq\left(\frac{a+f+c . s}{1-b-c . s}\right) \rho(x, T x)
$$

using symmetry, we can exchange a with b and c with e in (3.6) to obtain

$$
\rho\left(T x, T^{2} x\right) \leq\left(\frac{b+f+e . s}{1-b-e . s}\right) \rho(x, T x)
$$

and then

$$
\beta=\min \left(\frac{a+f+c . s}{1-b-c . s}, \frac{b+f+e . s}{1-b-e . s}\right)
$$

satisfies the conclusion of this lemma.

Proof of Theorem 3.4. Let $x_{0} \in M$ and $\left\{x_{n}\right\}$ be a sequence in $M$, such that

$$
x_{n}=T x_{n-1}=T^{n} x_{0}
$$

Now using lemma 3.1 we can show that

$$
\rho\left(x_{n+1}, x_{n}\right) \leq \beta^{n} \rho\left(x_{0}, x_{1}\right)
$$

Now, we show that $\left\{x_{n}\right\}$ is a Cauchy sequence in $M$.

Let $m, n>0$, with $m>n$

$$
\begin{aligned}
\rho\left(x_{n}, x_{m}\right) \leq & s\left[\rho\left(x_{n}, x_{n+1}\right)+\rho\left(x_{n+1}, x_{m}\right)\right] \\
& \leq s \rho\left(x_{n}, x_{n+1}\right)+s^{2} \rho\left(x_{n+1}, x_{n+2}\right) \\
& +s^{3} \rho\left(x_{n+2}, x_{n+3}\right)+\ldots \\
\leq & s \beta^{n} \rho\left(x_{0}, x_{1}\right)+s^{2} \beta^{n+1} \rho\left(x_{0}, x_{1}\right) \\
& +s^{3} \beta^{n+2} \rho\left(x_{0}, x_{1}\right)+\ldots
\end{aligned}
$$

when taking $\lim n \rightarrow \infty$ we get

$$
\lim _{n \rightarrow \infty} \rho\left(x_{n}, x_{m}\right)=0
$$

$\Rightarrow\left\{x_{n}\right\}$ is a Cauchy sequence in $M$. Since $M$ is complete, we consider that $\left\{x_{n}\right\}$ converges to $x^{*}$.

Now, we show that $x^{*}$ is fixed point of $T$. we have

$$
\begin{aligned}
& \rho\left(x^{*}, T\left(x^{*}\right)\right) \leq s\left[\rho\left(x^{*}, x_{n}\right)+\rho\left(x_{n}, T\left(x^{*}\right)\right)\right] \\
\leq & s\left[\rho\left(x^{*}, x_{n}\right)+\rho\left(T\left(x_{n-1}\right), T\left(x^{*}\right)\right)\right] \\
\leq & s\left[\rho\left(x^{*}, x_{n}\right)+a \rho\left(\left(x_{n-1}, T\left(x_{n-1}\right)\right)+b \rho\left(\left(x^{*}, T\left(x^{*}\right)\right)\right.\right.\right. \\
& +c \rho\left(x_{n-1}, T\left(x^{*}\right)\right)+e \rho\left(x^{*}, T\left(x_{n-1}\right)\right)+f \rho\left(x_{n-1}, x^{*}\right) \\
\Rightarrow & \rho\left(x^{*}, T\left(x^{*}\right)\right) \leq s\left[a \rho\left(x_{n-1}, x_{n}\right)+b \rho\left(x^{*}, T\left(x^{*}\right)\right)\right. \\
& \left.+c \rho\left(x_{n-1}, T\left(x^{*}\right)\right)+(e+1) \rho\left(x^{*}, x_{n}\right)+f \rho\left(x_{n-1}, x^{*}\right)\right]
\end{aligned}
$$

Taking $\lim n \rightarrow \infty$ we get

$$
\rho\left(x^{*}, T\left(x^{*}\right)\right) \leq s(b+c) \rho\left(x^{*}, T\left(x^{*}\right)\right)
$$

which contradicts unless $x^{*}=T\left(x^{*}\right)$.

Now, we show the uniqueness of fixed point.

Let $x$ and $y$ be two fixed points of $T$.

$$
\begin{aligned}
\Rightarrow x= & T(x), y=T(y) \\
\rho(x, y) & =\rho(T(x), T(y)) \\
& \leq a \rho(x, T(x))+b \rho(y, T(y))+c \rho(x, T(y)) \\
& +e \rho(y, T(x))+f \rho(x, y)
\end{aligned}
$$

$\leq(c+e+f) \rho(x, y)$ which is a contradiction. The proof is complete. 


\section{References}

[1] Hassen Aydi, Monica-Felicia Bota, Erdal Karapinar, and Slobodanka Mitrović, A fixed point theorem for set-valued quasicontractions in b-metric spaces, Fixed Point Theory and Application (2012), no. 88.

[2] Vasile Berinde, Generalized contractions in quasimetric spaces, (1993), no. 3, 3-9.

[3] Monica Boriceanu, Fixed point theory for multivalued generalized contraction on a set with two b-metrics, Babes-Bolyai University Mathematica Studia LIV (2009), no. 3, 1-14.

[4] Boriceanu M. Fixed point theory on spaces with vector-valued bmetrics, Demonstratio Mathematica XLII (2009), no. 4, 285-301.

[5] Boriceanu M. Strict fixed point theorems for multivalued operators in b-metric spaces. International Journal of Modern Mathematics 4 (2009), no. 2, 285-301.

[6] M. Bota, A. Molnar, and C. Varga, On ekeland's variational principle in b-metric spaces, Fixed Point Theory 12 (2011), no. 2 , 21-28.

[7] Renu Chugh, Vivek kumar, and Tamanna Kadian, Some fixed point theorems for multivalued mappings in generalized b-metric spaces, International Journal of Mathematical Archive 3 (2012), no. 3, 1198-1210.

[8] S. Czerwik, Contraction mappings in b-metric spaces, Acta Mathematica et Informatica Universitatis Ostraviensis 1 (1993), 511 .

[9] Czerwik S., Nonlinear set-valued contraction mappings in bmetric spaces, Atti. Sem. Mat. Fis. Univ. Modena 46 (1998), 263276.

[10] S. Czerwik, Krzyszt Dlutek, and S. L. Singh, Round-off stability of iteration procedures for operators in b-metric spaces, J. Natur. Phys. Sci. 11 (1997), 87-94.

[11] Czerwik S, Dlutek K, and Singh S L. Round-off stability of iteration procedures for set-valued operators in b-metric spaces, J. Natur. Phys. Sci. 15 (2001), 1-2.
[12] Wei Shih Du and Erdal Karapýnar, A note on cone b-metric and its related results: generalizations or equivalence?, Fixed Point Theory and Application 2012, no. 210.

[13] G. E. Hardy and T. D. Rogers, A generalization of fixed point theorem of reich, Canadian Mathematical Bulletin 16 (1973), 201206.

[14] Mehmet Kir and $\mathrm{H} \sqsubset$ ukmi Kiziltunc, On some well known fixed point theorems in b-metric spaces, Turkish Journal of Analysis and Number Theory, 1 (2013), no. 1, $13\{16$.

[15] Ion Marian Olaru and Adrian Branga, Common fixed point results in b-k-metric spaces, General Mathematics 19 (2011), no. 4, 51-59.

[16] Memudu O. Olatinwo and Christopher O. Imoru, A generalisation of some results on multi-valued weakly Picard mappings in bmetric space, Fasciculi-Mathematici 40 (2008), 45-56.

[17] Mădălina Păcurar, A fixed point result for $\varphi$-contractions on $b$ metric spaces without the boundedness assumption, Fascicyli Mathematici 43 (2010), 125-137.

[18] Pacurar M. Sequences of almost contractions and fixed pointsin bmetric spaces, Analele Universităţ de Vest, Timisoara, Seria Matematică Informatică XLVIII (2010), no. 3, 125-137.

[19] K. P. R. Rao and K. R. K. Rao, A common fixed point theorem for two hybridpairs of mappings in b-metric spaces, International Journal of Analysis 2013, no. 404838.

[20] Simeon Reich, Some remarks concerning contraction mappings, Canadian Mathematical Bulletins 14 (1971), no. 1, 121-124.

[21] Jamal Rezaei Roshan, Vahid Parvaneh, Shaban Sedghi, Nabi Shobkolaei, and Wasfi Shatanawi, Common fixed points of almost generalized $(\psi, \varphi)$ s-contractive mappings in ordered b-metric spaces, Fixed Point Theory and Application 2013, no. 159.

[22] Lu Shi and Shaoyuan $\mathrm{Xu}$, Common fixed point theorems for two weakly com-patible self-mappings in cone b-metric spaces, Fixed Point Theory and Applications 2013, no. 120.

[23] Shyam Lal Singh, Stephen Czerwik, and Krzysztof Król, Coincidences and fixed points of hybrid contractions, Tamsui Oxford Journal of Mathematical Sciences 24 (2008), no. 4, 401416. 